\title{
Cioran als Nihilist, Skeptiker und politischer Essayist
}

\author{
Edward Kanterian
}

Emil Cioran: Leidenschaftlicher Leitfaden II. Berlin 2013. Suhrkamp Verlag. 110 S. Emil Cioran: Über Deutschland. Aufsätze aus den Jahren 1931-1937. Berlin 2011. Suhrkamp Verlag. $231 \mathrm{~S}$.

Emil Cioran: Über Frankreich. Essay. Berlin 2010. Suhrkamp Verlag. 103 S.

Jürgen Grosse: Erlaubte Zweifel. Cioran und die Philosophie. Berlin 2014. Duncker \& Humblot. 319 S.

Emil Cioran gilt vielen als ein besonders eindeutiges Beispiel eines nihilistischen Denkers. Wie hier aufgezeigt werden soll, ist es aber nicht nur fraglich, ob der Nihilismus eine kohärente Position ist, sondern auch, ob Ciorans schillerndes und widersprüchliches Werk wirklich als das eines Nihilisten, oder auch nur eines Skeptikers, zu klassifizieren ist. Am ehesten, so scheint es, war er ein Pessimist bezüglich der Grenzen und Möglichkeiten menschlicher Zivilisation. Es wird dargelegt, dass dieser Pessimismus, von dem wir gerade heute manches wieder lernen können, seine Wurzeln in der deutschen Lebensphilosophie hat, die Cioran in seinem rumänischen Frühwerk, zu der auch eine faschistische Episode gehörte, umfassend rezipierte. Dies wird anhand der Diskussion von vier Neuerscheinungen von und über Cioran belegt.

Es ist vielleicht nicht ganz falsch, den Gang der europäischen Philosophie als die allmähliche Bewusstwerdung des menschlichen Geistes in seinen vielfältigen Formen und Widersprüchen zu beschreiben. Natürlich gab es dabei keinen geradlinigen Fortschritt. Wie die Kunst hängt auch die Philosophie von gewissen kontingenten Faktoren ab, etwa dem Auftreten besonders begabter Individuen, aber auch den sozialen und ideellen Konstellationen der jeweiligen Epoche. Das philosophische Bewusstsein war daher nicht immer auf der Höhe seiner eigenen Zeit (und ob es das heute ist, im Zeitalter des Managements und der richtungslosen Spezialisierung, sei dahingestellt). Ohnehin würden manche eher von einer Verfalls- als einer Fortschrittsgeschichte sprechen. Man denke an Nietzsches Genealogie der Moral, an Ludwig Klages Kritik der immer stärker werdenden Dominanz des Geistes über die Seele, oder an Heideggers Geschichte der Seinsvergessenheit. Aber auch diese Verfallsgeschichten sind von einem gewissen Optimismus getragen. Sie stellen Besserung in Aussicht: wenn wir einsehen, was in der Vergangenheit schiefgegangen ist, so können wir versuchen, etwas Neues zu errichten (eine neue Moral bei Nietzsche, der Seele wieder zu ihrem Recht verhelfen bei Klages) oder uns zumindest auf das Neue vorbereiten (durch Gelassenheit, bei Heidegger). Selbst die Geschichtspessimisten glauben, dass die menschliche Existenz wieder einen Sinn erlangen kann, nicht zuletzt durch ihre Schriften. 
Und selbst religiöse Positionen, die die Schlechtigkeit dieser Welt oder ihren illusionären Charakter betonen, wie z.B. die Gnosis, der Hinduismus und Buddhismus, setzen eine vollkommene oder wahre Realität (der Götter, des Bewusstseins) als Kontrast voraus. Auch die sogenannten russischen Nihilisten, z.B. Tkachev, Mikhailovsky, Chernyshevsky, Cedayev, ohne die Lenin und die russische Revolution nicht zu denken sind, fallen in diese Kategorie, denn sie waren Revolutionäre, die die Verderbnis der bisherigen Gesellschaft betonten und an eine paradiesische $\mathrm{Zu}$ kunft glaubten.

Hat es Pessimisten in einem radikaleren Sinn gegeben? Das wären Denker, die jedweden Sinn und Wert verneinen würden. Sie würden behaupten, es sei zu bedauern, dass wir existieren oder gar dass überhaupt etwas existiert, und würden lieber das Nichtsein dem Sein vorziehen. Man denkt hier vielleicht zuerst an Schopenhauer. Die Existenz auch nur eines Übels ist hinreichend, um uns über das Dasein der Welt zu betrüben. Sie ist etwas, »das im Grunde nicht sein sollte «". »Unser Dasein hat keinen Grund und Boden, darauf es fußte, als die dahinschwindende Gegenwart. $\mathbb{1}^{2}$ Und weil diese so vergänglich ist, lassen sich Sinn und Glück nicht denken, und das menschliche Dasein ist nichtig. Doch das gilt laut Schopenhauer nur für das phänomenale Dasein. Wir haben ein heimliches Bewusstsein von einem in uns liegenden "Born der Ewigkeit», einer zeitlosen Existenz, zu der wir durch die Verneinung des Willens gelangen können. Also gibt es für Schopenhauer hinter der Sinnlosigkeit doch eine Ebene des Sinns.

Vielleicht waren Schopenhauers "wilde Söhne " radikaler. ${ }^{3} \mathrm{Zu}$ diesen kann man bedingt auch Nietzsche zählen. Aber ein radikaler Nihilist war er nicht. Zwar stellte er fest, dass wir nach dem Tod Gottes durch ein unendliches Nichts irren (Die fröhliche Wissenschaft, $\$ 125$ ), doch natürlich war seine Umwertung aller Werte bloß als neue Sinngebung gedacht. Für Julius Bahnsen (1830-1881) besteht nicht nur das Seelenleben, sondern die ganze Welt aus unlösbaren Widersprüchen, aus der es keine Rettung gibt. Unsere Erlösungserwartung wird stets enttäuscht. Diese tragische Einsicht lässt sich nach Bahnsen aber durch Humor überwinden, indem wir Distanz zu unserem eigenen Schicksal gewinnen und es in der »Intellectualsphäre « mit ästhetischer Interesselosigkeit betrachten. ${ }^{4}$ Für Bahnsen gibt es also noch punktuelle Erlösung, wie für Schopenhauer in der Kunst. Eine radikalere Metaphysik entwickelte Philipp Mainländer (1841-1876), der

\footnotetext{
${ }^{1}$ Arthur Schopenhauer: Die Welt als Wille und Vorstellung. Zweiter Band, Kapitel 46.

2 Arthur Schopenhauer: Parerga und Paralipomena, $\$ 144$.

3 Siehe Richard Reschika: "Schopenhauers wilde Söhne«; in: Ders.: Philosophische Abenteuer. Elf Profile von der Renaissance bis zur Gegenwart, Tübingen 2001.

${ }^{4}$ Julius Bahnsen: Das Tragische als Weltgesetz und der Humor als ästhetische Gestalt des Metaphysischen, Leipzig 1931, S. 98.
} 
in seiner Philosophie der Erlösung $(1876,1886)$ behauptete, diese Welt sei aus dem Selbstmord Gottes hervorgegangen. Wir sind seine Überreste, das Ergebnis eines ursprünglichen Aktes der Vernichtung. Denn Gott war ursprünglich das einzige Wesen und ihm standen nur zwei mögliche Willensakte zur Verfügung - so zu bleiben, wie er war, oder aufzuhören zu existieren. Da er aber schon so war, wie er war, wäre sein Fortbestand keine positive Handlung gewesen, sondern bloß die Unterlassung, sich zu vernichten. Also war seine Vernichtung die einzige mögliche positive Tat, die ihm offen blieb. Denn seine fortgesetzte Existenz wäre ja das Zeichen seiner Schwäche und Unfreiheit gewesen, und hätte ihn leiden lassen. Existieren bedeutet also Leiden, selbst für Gott.

Da Gott aber nicht die Freiheit hatte, sofort ins Nichtsein überzugehen, da sein Wesen ihn notwendig bestimmte, irgendwie zu sein, wählte er den Umweg des Zerfalls in die Vielheit, d. h. die Welt, als das Mittel zu seiner eigenen Vernichtung. ${ }^{5}$ In ihrem Urzustand besteht die Welt aus Individuen, die von einer »ohnmächige[n] Sehnsucht [...] nach dem absoluten Tode « bestimmt sind. ${ }^{6}$ In uns Menschen manifestiert sich der Wille zum Tode gelegentlich durch eine tiefe Sehnsucht nach Ruhe. ${ }^{7}$ Wir sind also Teile eines verwesenden Gottes ${ }^{8}$, eines von langer Hand angelegten gigantischen Dramas (einer "Theothanatologie») und befinden uns selbst, gerade durch unsere Existenz, auf dem Weg ins Nichts, dem letzten Zweck des Universums. In seinem Kampf gegen die anderen wird jedes Individuum daran gehindert, den absoluten Tod sofort zu finden. Wie bei Gott gibt es auch bei uns ein retardierendes Moment unseres Dranges zum Nichts. Da aber jedes Individuum sich an diesem Konflikt aufreibt, nimmt seine "Kraftsumme« insgesamt ab und damit auch die Kraftsumme des Universums, bis sie schließlich gegen Null tendiert. Das "Nichts ist also in dieser Konzeption eine Art entropischer Stillstand, nicht aber Nicht-Existenz, was Mainländers Nihilismus doch erheblich abschwächt. Außerdem ist Mainländer im Grunde kein Pessimist, ja nicht einmal ein moralischer Nihilist, denn sein Universum, und damit unser Leben, ist keineswegs sinnlos, sondern bewegt sich auf seine Erlösung hin. Das geschieht sogar mit einer so zielstrebigen Notwendigkeit, dass wir Mainländer genauso gut auch als Optimisten bezeichnen können. Es kann daher nicht stim-

${ }^{5}$ Vgl. Philipp Mainländer: Die Philosophie der Erlösung, Berlin 1876, S. 323 ff. Mainländer nennt diesen Umweg das "transzendente Verhängnis» (S. 329).

${ }^{6}$ Ebd., S. 328.

${ }^{7}$ Ebd., S. 334.

${ }^{8}$ Siehe Ulrich Horstmann: „Der verwesende Gott. Philipp Mainländers Metaphysik der Entropie«; in: Winfried H. Müller-Seyfarth (Hg.): Die modernen Pessimisten als décadents. Von Nietzsche zu Horstmann. Texte zur Rezeptionsgeschichte von Philipp Mainländers Philosophie der Erlösung, Würzburg 1993. 
men, dass das menschliche Leben keinen Wert hat, wie seine Position manchmal resümiert wird. Er schrieb zwar, auf unsere Existenz bezogen, "Nichtsein ist besser als Sein «", doch das impliziert zum einen eine Werteskala, zum anderen liegt der Wert oder Sinn des menschlichen Lebens nach seiner Metaphysik darin, dass der Mensch zu seiner und der universalen Erlösung beiträgt. So ist auch Mainländers Selbstmord zu verstehen - als die logische Konsequenz einer Philosophie der Erlösung.

Das Problem (wenn es denn eines ist) mit den bisher angeführten Positionen liegt darin, dass sie alle direkt oder indirekt Erlösungsangebote und Werteskalen beinhalten. Anders scheint der Fall bei dem rumänischen Denker Emil Cioran (1911-1995) zu liegen, der vielen als der Nihilist schlechthin gilt. Schon die Titel seiner Bücher suggerieren das: Auf den Gipfeln der Verzweiflung, Das Buch der Täuschungen, Lehre vom Zerfall, Vom Nachteil, geboren zu sein, Syllogismen der Bitterkeit, Der Absturz in die Zeit, Die verfehlte Schöpfung, Gevierteilt, usw. ${ }^{10}$ Und doch kann man auch bei ihm fragen: Kann man von Zerfall, Absturz, Verfehlung sprechen ohne eine Werteskala im Hintergrund?

Dass unsere Existenz keinen Sinn hat und haben kann, ist eines der Leitmotive Ciorans, das er aus immer neuen Blickwinkeln, oft in einprägsamen oder provokanten Aphorismen, erfasste. Man braucht nur wahllos eine Seite in seinem Werk aufzuschlagen, um Zeilen wie die folgenden zu lesen. "Mein Auftrag ist es, die Menschen aus ihrem ewigen Schlaf zu erwecken, obwohl ich weiß, dass ich damit ein Verbrechen begehe und dass es tausend Mal besser wäre, wenn ich sie weiter schlafen ließe, da ich ihnen, wenn ich sie erwecke, nichts anzubieten hätte« (Cahiers 1957-1972, S. 682). ${ }^{11}$ "Nicht geboren zu sein ist unbestreitbar die beste Formel, die es gibt. Leider steht sie niemandem zur Verfügung.«; »Tief in seiner Seele sucht der Mensch wieder zu jenem Zustand zu finden, den er vor dem Bewusstsein hatte. Die Geschichte ist nur der Umweg, den er dafür einschlägt«; "Die Mühe, sich umzubringen, lohnt nicht, weil jeder Selbstmord zu spät kommt" (Vom Nachteil, geboren zu sein, C, S. 898, 828, 756). "Je mehr wir das Gefühl unserer Nichtigkeit haben, umso mehr verabscheuen wir die anderen; wenn wir von der Gewissheit des Nichts, das wir sind, erleuchtet sind, hören die anderen, für uns, sogar zu sein auf« (Der

\footnotetext{
9 Mainländer: Philosophie der Erlösung, a. a. O., S. 208.

${ }^{10}$ Für Resümees dieser Bücher, siehe das unlängst erschienene, äußerst nützliche Nachschlagewerk von Jürgen Grosse: Erlaubte Zweifel. Cioran und die Philosophie, Berlin 2014.

${ }_{11}$ Mit Ausnahme der besprochenen Bücher, gehen alle Zitate aus Ciorans Werken auf die Übersetzung des Rezensenten zurück. "C«, gefolgt von der Seitenangabe, steht für die Gesamtausgabe von Ciorans französischen Werken: Emil Cioran, Oeuvres, hrsg. von Nicolas Cavaillès, Paris 2011.
} 
Absturz in die Zeit, C, S. 567). "Der Mensch ist nur dann zufrieden, wenn er aufhört, Mensch zu sein« (Gevierteilt, C, S. 1005).

»Womöglich ist der Tag nicht fern, an dem wir, unfähig, die Furcht, die wir angesammelt haben, auszuhalten, ihrer Last nachgeben werden. [...] Dann werden wir tiefer als die Toten hausen, voller Neid über die Ruhe und Glückseligkeit dieser gleichgültigen Schädel, die sich in einer ewigen Unterbrechung befinden, dieser abgespannten und bescheidenen Skelette, endlich erlöst von der Ungebührlichkeit des Blutes und den Forderungen des Fleisches. In der Dunkelheit herumstochernd werden wir zumindest die Genugtuung haben, uns nicht mehr gegenseitig anblicken zu müssen, die Freude, unseren Antlitz verloren zu haben« (C, S. 932 f.).

Die Schriften Ciorans behandeln auch andere Themen. Der Autor tritt dabei nicht immer so unversöhnlich auf. So sind seine Essays über Beckett oder Valéry, zu finden in den Widersprüchlichen Konturen, voller Eleganz und Einfühlungsgabe, und Cioran gelingt es, auf stilistisch meisterhafte Weise, diese schwer zugänglichen Autoren verständlicher zu machen. Doch der Generalbass seines Denkens scheint immer der gleiche zu sein: Der Mensch ist ein abscheuliches, erbärmliches Wesen, verdammt zur Vernichtung, als Individuum wie als Spezies, und es gibt keine Rettung für ihn. Seine Erlösungsversuche und Fortschrittsideen, ob in der Religion, Philosophie, Politik, Wissenschaft, sind allesamt eitle Phantasien.

Und doch können wir Cioran nicht als radikalen Nihilisten bezeichnen. Seine Unkenrufe beziehen sich, anders als bei Hume, mit dem er manches gemeinsam hat, fast ausschließlich auf den Menschen, nicht aber auf andere Lebewesen. ${ }^{12}$ Zwar schreibt Cioran oft, dass die Katastrophe unserer Existenz darin besteht, geboren worden zu sein, aber der eigentliche Sündenfall besteht darin, als Wesen mit Bewusstsein geboren worden zu sein. Daher schreibt er: »In jedem Wesen, das nicht weiß, dass es existiert, in jeder Lebensform ohne Bewusstsein gibt es etwas Heiliges. Wer nie das Pflanzenreich beneidet hat, hat das Drama des Menschen nicht zur Kenntnis genommen " (Der Absturz in die Zeit, C, S. 614). Die Existenz von Wesen ohne Bewusstsein hat daher keine katastrophale Dimension, bzw. eine

12 Hume schrieb: »The whole earth, believe me, Philo, is cursed and polluted. A perpetual war is kindled amongst all living creatures. Necessity, hunger, want, stimulate the strong and courageous: Fear, anxiety, terror, agitate the weak and infirm. The first entrance into life gives anguish to the new-born infant and to its wretched parent: Weakness, impotence, distress, attend each stage of that life: and it is at last finished in agony and horror" (David Hume: Principal Writings on Religion, Oxford 1993, S. 96). Zu Ciorans Verhältnis zu Hume, siehe Grosse: Erlaubte Zweifel, a.a. O., S. 64 ff. Große übergeht allerdings Humes Schriften über die Religion, die nicht nur für ein Verständnis Humes unabdingbar sind, sondern auch für einen Vergleich zwischen Hume und Cioran. 
umso geringere, je weniger sie entwickelt sind. ${ }^{13}$ So schreibt Cioran: "Besser Tier als Mensch, Insekt als Tier, Pflanze als Insekt, usw. Die Rettung? Alles was den Einfluss des Bewusstseins vermindert und seine Vormachtstellung untergräbt« (Vom Nachteil, geboren zu sein, C, S. 756).

Allerdings ergeben sich hier zwei Probleme. Zum einen ist es nicht klar, was es heißt, über einen Menschen zu sagen, es wäre besser (gewesen), wenn er eine Pflanze, oder gar ein Stein (gewesen) wäre. Die Aussage »Es wäre besser gewesen, dass X ein Y gewesen wäre« macht nur Sinn, wenn "X hätte ein Y sein können« Sinn macht. Doch so wie die Aussage: "Dieser Apfel hätte ein Stein sein können«, keinen Sinn macht, macht es auch keinen Sinn zu sagen "Ich hätte eine Pflanze oder ein Stein sein können«. Also macht es auch keinen Sinn zu sagen, »Ich hätte besser ein Stein sein sollen«. Die Identitätskriterien von Substanzen sind nicht derart elastisch. Außerdem stellen wir fest, dass auch Cioran, wie die angeblichen Nihilisten vor ihm, eine Werteskala besitzt. Demnach wäre es am besten, wenn man ein unbelebter Gegenstand wäre. Eine solche Aussage macht nach dem gerade Gesagten nur noch dann einen Sinn, wenn man sie als eine Rechtfertigung des Selbstmords versteht.

Cioran schrieb oft über seine »Begegnungen« mit dem Selbstmord (z. B. in Die verfehlte Schöpfung). Er sah die Möglichkeit des Selbstmords als sinnstiftend an. Zu wissen, dass man sich umbringen kann, den Zeitpunkt seines Todes bestimmen kann, sei eine wichtige Selbsteinsicht. "Auch nur ein Messer anzuschauen und sich darüber klar zu werden, dass es nur von einem selbst abhängt, ob man von ihm einen bestimmten Gebrauch macht, gibt einem ein Gefühl der Überlegenheit, das in Megalomanie enden kann. Wenn der Gedanke daran, mit allem Schluss zu machen, uns in den Bann zieht, öffnet sich ein Raum vor uns, eine große Möglichkeit außerhalb der Zeit und selbst der Ewigkeit, [...] eine Hoffnung des Sterbens jenseits des Sterbens. Sich umzubringen bedeutet daher mit dem Tod zu konkurrieren« (Die verfehlte Schöpfung, C, S. 659). Man bemerke, es geht hier um den Gedanken an den Selbstmord, nicht um den Selbstmord selbst. Cioran rechtfertigte den Selbstmord also nicht als wirklich durchzuführende Tat. So ist wohl sein Aperçu zu verstehen, er hätte ohne die Möglichkeit des Selbstmords sich schon vor langer Zeit umgebracht. ${ }^{14}$ Cioran verglich den mentalen Zustand des Selbstmörders zuweilen mit dem des Wahnsinns, und schrieb Sätze wie die folgenden: „Warum ich nicht Selbstmord verübe? Weil mich sowohl das Leben als auch der Tod anwidern«;

13 Das erinnert an Benns Gesänge: „Oh, dass wir unsere Ur-ur-ahnen wären./Ein Klümpchen Schleim in einem warmen Moor./...] Schon ein Libellenkopf, ein Möwenflügel/Wäre zu weit und litte schon zu sehr." (Gottrried Benn: Gedichte, Frankfurt a.M. 2004, S. 25.)

14 Vgl. The Independent, 2.12.1989, S. 18. 
"Wenn das Leiden kein Erkenntnismittel wäre, wäre der Selbstmord Pflicht«; "Widerlegung des Selbstmords: ist es nicht unelegant, eine Welt zu verlassen, die sich so bereitwillig in den Dienst unseres Trübsinns stellt?

Es ist vor allem unklar, wie wir Ciorans Bedauern darüber, dass wir Lebewesen mit Bewusstsein sind, verstehen sollen. Es liegt auf der Hand, dass Absenz von Bewusstsein keine Präsenz von Glück impliziert. Der Stein ist weder glücklich noch unglücklich. Wir können ihn nicht darum beneiden, dass er nicht unglücklich ist, und auch nicht sagen, dass es für ihn besser ist, dass er ein Stein und kein Mensch ist. Nur ein höher entwickeltes Lebewesen kann glücklich sein. Dabei darf es sich laut Cioran um kein derart weit entwickeltes Lebewesen handeln, dass es um die Endlichkeit allen Glücks, die Vergänglichkeit jedes Genusses weiß. »Zu betrachten ohne zu verstehen, das ist das Paradies. Die Hölle wäre demnach der Ort, an dem du verstehst, zuviel verstehst (Vom Nachteil, geboren zu sein, C, S. 753). Das Tier kann noch nicht betrachten, ist noch zu sehr im Augenblick der Empfindung verhaftet, der erwachsene Mensch wiederum versteht schon zuviel. Die Kindheit scheint also der Zwischenzustand zu sein, in dem das höchste Glück erreicht wird. Müssten wir dann nicht frohen Mutes Kinder in die Welt setzen, sind sie doch die wahrhaft Glücklichen? Zwar schreibt Cioran, dass er seine Kinder erwürgen würde, wenn er welche hätte, doch das ist sicherlich eine Zuspitzung seiner Überzeugung, dass wir uns auf die Apokalypse zubewegen (Vom Nachteil, geboren zu sein, C, S. 835).

Als Kontrast zum naiven Fortschrittsoptimismus, von dem auch heutige Philosophen nicht frei sind, ${ }^{15}$ ist dieser Pessimismus durchaus heilsam. Der einzelne Mensch geht ohnehin seiner Vernichtung entgegen. Das gilt aber auch für die ganze Spezies, glaubt Cioran. Und selbst wenn die Apokalypse nicht plötzlich eintreten sollte, wird die Menschheit Opfer ihres eigenen Fortschritts, ihrer theoretischen Neugierde, ihres Willens zur Macht werden. So heißt es in seinem Spätwerk Gevierteilt: "Das Ende des geschichtlichen Prozesses ist von jetzt an unerbittlich, ohne daß man deswegen sagen kann, ob es schleppend oder rasant sein wird. Alles weist darauf hin, daß es mit der Menschheit bergab geht, trotz oder vielmehr wegen ihrer Erfolge« (C, S. 925). Doch schon in der Lehre vom Zerfall steht: "Nichts weist darauf hin, dass sie noch einen Rivalen von Bach oder

${ }^{15}$ Hier sei ein prominentes Beispiel zitiert: "Since human history may be only just beginning, we can expect that future humans, or supra-humans, may achieve some great goods that we cannot now even imagine. In Nietzsche's words, there has never been such a new dawn and clear horizon, and such an open sea« (Derek Parfit: On What Matters. Volume Two, Oxford 2011, S. 618). Für eine weitere Diskussion von Ciorans Fortschrittsund Geschichtsskepsis, siehe Grosse: Erlaubte Zweifel, a.a. O., S. $116 \mathrm{ff}$. 
Shakespeare wird zeitigen können. Die Dekadenz tritt zuerst in den Künsten in Erscheinung; die 'Zivilisation wesung« (C, S. 114). Die durchgängige Rationalisierung und Entzauberung wird sich gegen ihre Lenker kehren: »der Zukunft überdrüssig, und erst recht unserer selbst, haben wir den Saft der Erde ausgepresst und die Himmel entblößt. Weder die Materie noch der Geist können noch unsere Träume nähren; das Universum ist genauso ausgedorrt wie unser Herz. [...] Das Abenteuer endet, das Bewusstsein gibt seinen Geist auf, unsere Lieder ersterben" (C, S. 115).

An der Zukunft findet Cioran nichts auch nur annähernd Schönes, Wertvolles oder Bedeutsames. Sein verklärender Blick richtet sich auf die Vergangenheit. So gibt Cioran freimütig zu, dass seine Kindheit glücklich war, ja "mehr als glücklich", »erhaben selbst im Leid« (C, S. 888) ${ }^{16}{ }^{16}$ Diese Nostalgie wird in Vom Nachteil geboren zu sein ins Metaphysische gewendet: "Jene verschwindende Lichtspur in jedem von uns, die ihren Ursprung weit vor unserer Geburt hat, weit vor jeder Geburt, ist das, was wir bewahren müssen, wollen wir die Verbindung mit jenem weit entfernten Licht wiederbeleben, von dem wir getrennt wurden, ohne dass wir den Grund jemals wissen werden" (C, S. 856). Und doch schreibt Cioran auch gegen die Tatsache unserer Geburt an, ja sogar gegen die Existenz dieser Welt, vor allem in Vom Nachteil geboren zu sein. "Nicht geboren zu sein ist unbestreitbar die beste Formel, die es gibt. Leider steht sie niemandem zur Verfügung." (C, S. 898); "Nicht geboren worden zu sein, daran nur zu denken, welches Glück, welche Freiheit, welcher Raum!«(C, S. 749). "Niemand hat diese Welt so sehr geliebt wie ich, und trotzdem, selbst wenn man sie mir auf dem silbernen Tablett serviert, hätte ich ausgerufen: ¿Zu spät, zu spät! « (C, S. 899). Demnach wäre es besser gewesen, wenn ich nicht existiert hätte, ja mehr noch, wenn die Welt nicht existiert hätte. Denn: "Existenz = Leiden. Diese Gleichung scheint mir evident zu sein« (C, S. 824).

Doch wie sind diese Aussagen zu verstehen? Merken wir zuerst einmal an, dass wir es hier mit keinen wertnihilistischen Aussagen zu tun haben. Wenn wir sagen, etwas sei besser als etwas anderes, vollziehen wir eine Wertung, in diesem Fall die Wertung, dass das Nichtsein dem Sein vorzuziehen ist. Der Wertenihilismus lehnt aber alle Werte ab. Cioran ist somit kein Wertenihilist, und es bleibt weiterhin eine offene Frage, ob überhaupt irgendein Denker es je war. Nun ergeben sich zwei weitere Probleme, die mit der Bedeutung der kontrafaktischen Aussage, „Es wäre besser gewesen, wenn . . . zusammenhängen. Erstens sind solche Aussagen ganz unproblematisch zu nehmen, wenn man sie hinsichtlich der Möglichkei-

\footnotetext{
${ }^{16}$ Vgl. auch Grosse: Erlaubte Zweifel, a. a. O., S. $214 \mathrm{ff}$.
} 
ten eines Individuums macht. „Es wäre für Tom besser gewesen, wenn er Arzt geworden wäre " - dieser Satz bewertet eine alternative Laufbahn von Tom, und setzt dabei die Existenz von Tom in der faktischen und der kontrafaktischen Situation voraus. Bei "Es wäre besser gewesen, wenn Tom nicht existiert hätte « ist das nicht der Fall. Für wen wäre das besser gewesen? Wir können nicht sagen »Für Tom", denn wenn er nicht existiert hätte, wäre gar nichts für ihn besser oder schlechter gewesen. Die De-reLesart solcher Sätze funktioniert nicht. Vielleicht haben solche Aussagen aber eine andere Funktion. Man kann sie im sozialen Sinne nehmen (»Es wäre für Toms Mitmenschen besser gewesen, wenn er nicht existiert hätte«) oder im stark emotiven Sinne ("Toms Leben ist voller Pein und Qual«). Doch dann kommen solche Aussagen nicht als nihilistische in Frage.

Zweitens kann man sich fragen, ob man die kontrafaktische Aussage im absoluten Sinne nehmen kann, nämlich als "Es wäre besser gewesen, wenn es nichts gegeben hätte«. Hätte es nichts geben können? Es ist nicht ausgemacht, dass hier eine reale Möglichkeit beschrieben wird. Zumindest hat Kant in seiner Schrift Der einzig mögliche Beweisgrund zu einer Demonstration des Daseins Gottes (1763) bestritten, dass es nichts hätte geben können; denn jede Möglichkeit setzt etwas Existierendes voraus, das "Materiale zu irgend etwas Denklichem" (Ak 2:78). Gäbe es nichts, so gäbe es auch keine Möglichkeit, was für Kant ein Unding ist (Ak 2:79). Auch Bede Rundle hat in Why there is Something rather than Nothing (Oxford 2009) gegen die These argumentiert, dass es buchstäblich nichts hätte geben können. Denn "buchstäblich nichts" hat keine Bedeutung. Wenn wir von "nichts" sprechen, meinen wir das immer in einem relationalem Sinn ("Es gibt nichts im Kühlschrank«, "Es gibt nichts in der Küche« etc.).

Halten wir zwei Einsichten fest. Erstens können wir nicht alle Werte verneinen, und zweitens macht es keinen Sinn zu sagen, dass im absoluten Sinne die Nichtexistenz der Existenz vorzuziehen ist. Cioran mag zwar manchmal als Wertenihilist auftreten, doch er verwickelt sich dabei, wie gesehen, in Ungereimtheiten. Aber auch um seinen ontologischen Nihilismus ist es nicht besser bestellt. Er kulminiert in der Aussage: "Alles ist nichts, einschließlich des Bewusstseins von nichts" (Gevierteilt, C, S. 993). Ähnlich schreibt er in Von Tränen und von Heiligen: "Niemand existiert - eine notwendige und erbauende Schlussfolgerung; wahrscheinlich hat nie jemand existiert ${ }^{17}$; »Ohne Gott ist alles nichts. Und Gott? Das höchste Nichts ${ }^{18}$. In seiner Erstlingsschrift Auf den Gipfeln der Verzweiflung heißt es: "Nur das Nichts bleibt uns zu wählen. «19

17 Cioran: Lacrimi şi sfinţi, Bukarest 1991, S. 166.

18 Cioran: Syllogismen der Bitterkeit, S. 62.

19 Cioran: Pe culmile disperării [Auf den Gipfeln der Verzweiflung], Bukarest 1990, S. 114 . 
Es bedarf keiner großen Mühe, solche Sätze, so dramatisch sie klingen mögen, wie ein Kartenhaus in sich zusammen stürzen zu lassen. Da schon die Aussage "Alles ist nichts« etwas ist (nämlich eine Aussage), ist die Aussage natürlich falsch. Außerdem könnten wir nicht einmal diese Aussage machen, wenn das Bewusstsein von nichts nichts wäre. Wenn »Nichts existiert" eine notwendige Schlussfolgerung ist, "gibt« es immerhin die Logik. Es ist aber unklar, welche die Prämissen einer solchen Schlussfolgerung wären. Wenn sie erbauend ist, hat sie sogar einen Nutzen, einen Wert. Wenn es bloß wahrscheinlich ist, dass nie jemand existiert hat, dann kann es nicht notwendig sein, dass nichts existiert. Außerdem: welche Evidenz könnten wir dafür und dagegen anführen, dass nie jemand existiert hat? Wenn Gott das höchste Nichts ist, ist er ein etwas, da er sich sonst von einem "niedrigen« Nichts nicht unterscheiden würde. Wenn Gott nichts ist, wird aus "Ohne Gott ist alles nichts" "Ohne nichts ist alles nichts«, was nicht einmal eine klare Bedeutung hat. Worauf bezieht sich überhaupt "alles« in "Alles ist nichts«? Jede Antwort, die nicht »Nichts« ist, widerlegt die Aussage, während die Antwort »Nichts« bloß eine Tautologie anzeigt (»Nichts ist nichts«), die nichts über die Existenz oder Nicht-Existenz der Dinge sagt. Schließlich: Wenn wir das Nichts wählen, wählen wir im Grunde nichts - es gibt also gar keine Wahl. Wir haben es hier mit lauter Scheinsätzen zu tun.

Ciorans nihilistische Behauptungen ließen sich auf diese Weise weiter zerpflücken. Doch drücken sie wirklich in diesen swörtlichen Lesarten seine Überzeugungen aus? Das ist zu bezweifeln. Zu Sylvie Jadeau sagte er in einem Gespräch von 1990: "Ich bin kein Nihilist, auch wenn die Verneinung mich immer versucht hat . In den Cahiers schrieb er: »Mein ganzes Unglück ergibt sich aus der Tatsache, dass ich zu sehr am Leben hänge. Ich kenne keinen, der es so sehr liebt wie ich«(S. 317). Von seiner Liebe zum Leben sprach Cioran immer wieder.

War Cioran vielleicht eher ein Skeptiker? „Ich habe den Zweifel in allen Künsten gesucht" schreibt er in der Lehre vom Zerfall (C, S. 100). Und in Dasein als Versuchung heißt es: "Der Skeptizismus, zuerst Instrument oder Methode, wurde schließlich zu einem Teil von mir, zu meiner Physiologie, der Bestimmung meines Körpers, meinem viszeralen Prinzip, dem Übel, von dem ich mich nicht heilen kann, das mich aber auch nicht tötet« (C, S. 336). Doch dies ist kein stabiler Zustand. Cioran forciert den Skeptizismus manchmal bis zu seinem Bruchpunkt. So lesen wir in den Syllogismen der Bitterkeit: "Es kommt eine Zeit, da dem Skeptiker nichts mehr zu bezweifeln übrig bleibt und er sein Urteil endgültig aussetzt. Was bleibt ihm zu tun? Sich zu amüsieren oder zu erschlaffen - die Frivolität oder die Animalität« (C, S. 192). Doch strenggenommen setzt die Entscheidung zur Frivolität oder Animalität eigentlich weitere Urteile voraus - der 
Skeptiker scheitert also. Im Grunde sollte er gar nichts tun. Das suggeriert eine Passage aus dem Frühwerk: "Wie gerne wünsche ich mir, dass eines Tages alle Menschen, die einer Beschäftigung nachgehen oder eine Bestimmung haben, die verheiratet oder ledig sind, jung oder alt, Frauen oder Männer, ernst oder oberflächlich, traurig oder heiter, ihre Wohnungen und Büros verlassen, allen Pflichten entsagen, auf die Strasse gehen und nichts mehr tun wollen« (Lacrimi şi sfinţi, S. 79). Doch buchstäblich nichts tun, ist unmöglich, denn auch Weigerung und Enthaltung sind selbst Handlungen. In der Lehre vom Zerfall stellt Cioran den Skeptiker gar als Dogmatiker dar. Das tägliche Leben wird von Vorurteilen und Gewissheiten getragen, die der Skeptiker bloß in anderer Gestalt reproduziert. Selbst jener, der die üblichen Gewissheiten abzuschütteln vermag, "verbleibt in der Wüste seiner Einsamkeit ein Fanatiker", ein Fanatiker seiner selbst, seiner Obsessionen. „Der Skeptiker selbst, verliebt in seine Zweifel, stellt sich als Fanatiker des Skeptizismus heraus« (C, S. 58). Um sich selbst zu entkommen, müsste man zum instinktlosen Wesen werden, doch das ist unmöglich. "Der Mensch, der sich nicht selbst anbetet, ist noch nicht geboren worden« (C, S. 59). Und so schlussfolgert Cioran, dass keine Kritik der Vernunft jemals den Menschen aus seinem dogmatischen Schlummer wecken wird. Die Philosophie mag unsere Gewissheiten lockern, aber »die auf ihren Dogmen dösende Kreatur von Grund auf zu erschüttern« vermag sie nicht.

An diesem Humeschen Punkt angelangt, möchte man denken, dass man Ciorans philosophische Grundüberzeugung gefunden hat, eben die eines moderaten Skeptizismus. Allein, es ist nicht ausgemacht, ob Cioran eigentlich philosophische "Grundüberzeugungen« hatte. So schreibt er in Gevierteilt: "Ein glamouröser Hokus-Pokus, das also ist die Philosophie. Doch letztendlich ist alles Hokus-Pokus, außer dieser Aussage selbst, die zu einer Ordnung von Propositionen gehört, die niemand zu bezweifeln wagt, weil sie aus einer unverifizierbaren Gewissheit hervorgehen, einer Gewissheit, die scheinbar noch vor dem Gehirn da war« (C, S. 998). Die hier beschworene Idee von einer unvordenklichen, primordialen Gewissheit erinnert an die oben zitierte Metapher von der Lichtspur vor unserer Geburt. Doch wenn alles Hokus-Pokus ist, wie sind wir selbst noch zu dieser Gewissheit berechtigt?

Überblicken wir den bisherigen Gang der Überlegung, so müssen wir feststellen, dass man Cioran auf keine "harte« philosophische These festlegen kann. Er ist weder Nihilist noch Skeptiker. Mal verneint und verdammt er die Existenz, mal bejaht er sie. Er zweifelt alles an, aber auch den Zweifel. Die nostalgische Gewissheit, auf die er sich dabei beruft, steht selbst ohne Begründung im Raum. Wer nach einer systematischen, kohärenten Philosophie sucht, ist bei ihm an der falschen Adresse. Auf eine 
solche Philosophie arbeitete er auch nie hin. Er schrieb für die Augenblicke, und diese waren je anderen Stimmungen unterworfen. Seine Texte sind genialisch überspitzte Ausdrücke bestimmter Seelenlagen und der Versuche ihrer Überwindung. So sagte er zu seinem Freund Wolfgang Kraus: "Meine Aphorismen könnten so oder ganz anders lauten. Ihr Inhalt ist ohne Bedeutung. Die sprachliche Nuance, die Pointe, der Witz, der Höhepunkt sind das Wesentliche. So sind [meine] Werke zu verstehen" (30.12.1976). Und weiter: »Ich schreibe Paradoxa auf, geistige Zustände. In meinem letzten Buch (Das Ende der Geschichte) schreibe ich: WWenn ich auf die Strasse gehe und die Menschen sehe, kommt mir nur ein Wort in den Sinn: Auslöschung`. Was nicht wortwörtlich zu nehmen ist« (18.2.1980). Und so ist es auch verständlich, wenn Cioran dem Freund anvertraut, seine Schriften seien nur Reste, Auswürfe, Müll, »das Komplement dessen, was [Cioran] in Wirklichkeit ist«. Denn: "Das Leben ist wichtig, nicht das Schreiben" (22.2.1981). ${ }^{20}$

Wir können hier also von keiner Philosophie im gewöhnlichen Sinne sprechen. Ciorans Schreiben hat therapeutische Funktion. Genauer noch: Der Akt des Schreibens ist für ihn Therapie. Man könnte fast von einem magischen Vorgang bei ihm sprechen: Cioran nennt die Verzweiflung beim Namen, um sie zu bewältigen (wie auch Claudia Dorchain argumentiert hat). Um ihn zu verstehen, müssen wir bereit sein, einen von vielen Dämonen umgetriebenen Denker bei dem Versuch, sich selbst zu heilen, über die Schulter zu schauen. Ein Leser, der sich den wechselnden Stimmungen, den sich oft widersprechenden Behauptungen, den tiefschürfenden Alltagsbeobachtungen, den mal skandalösen, mal hysterischen, mal geistreichen Bemerkungen, den verzweifelten oder resignierten Ausrufen dieses Autors nicht hingeben kann, ohne sogleich zu bewerten und zu widerlegen, wird keinen Zugang zu ihm finden. Man muss sich von Cioran treiben lassen, gleichsam in den philosophischen Halbschlaf.

Gerade weil der menschliche Geist ein so weites Feld ist, voller seltsamer Blüten und Unkräuter, die dem engeren Blickfeld der akademischen Philosophie entgehen, ist Cioran wertvoll. Jürgen Große kontrastiert die "ursprüngliche Wildheit«, aus der heraus Cioran schreibt, mit der Sachlichkeit professioneller Philosophen. Dieser Kontrast ist nicht zufällig, sondern entspricht einer Tendenz moderner Gesellschaften, nämlich dem Auseinanderdriften von subjektiver Bildung und objektivem Wissen, von Weltanschauung und Gelehrsamkeit. ${ }^{21}$ Doch Cioran reflektiert diesen Riss nicht als Guru oder Popularphilosoph. Ihm sind nicht nur die »ar-

\footnotetext{
${ }^{20}$ Siehe Wolfgang Kraus: Scrisori către Wolfgang Kraus, Bukarest 2009, S. 259 ff.

${ }^{21}$ Vgl. Grosse: Erlaubte Zweifel, a. a. O., S. 144.
} 
beitstüchtige Gelehrsamkeit», sondern auch die Naivitäten gängiger Weltanschauungen verdächtig, auf die "allzu leicht erlösbare Seelen« hereinfallen. ${ }^{22}$ Dabei bleibt seine eigene Position instabil. Wir sollten seine "metaphysische Exaltation« daher nicht über alle Maßen loben, als ob Cioran es doch vermocht hätte, Intellekt und Existenz, Geist und Leben, Denken und Sache zu versöhnen, wie selbst ein so treuer Leser wie Große anzunehmen scheint. ${ }^{23}$ Doch wie auch Große betont, war Cioran immer ein Denker des »Risses«, der Kluft, des Abgrunds. ${ }^{24}$ Darin liegt sein größter Wert für uns, in seiner "Exzentrik». Wir, die "professionellen Philosophen", können mit seiner Hilfe die tiefen Risse um und in uns überhaupt erst gewahren.

Cioran verweist uns auf die tragischen und widersprüchlichen Konturen menschlicher Existenz und Geschichte, für die der theoretisch Geschulte heute eher den Blick verloren hat. "Abstract, decontextualised, psychologically jejune, detached from the drama of the human journey« - so hat ein bekannter britischer Denker die heutige Philosophiewissenschaft charakterisiert. ${ }^{25}$ Und tatsächlich ist die Philosophie in der Gegenwart oft bloß ein weiterer Aspekt der modernen, auf endlosen Fortschritt und Wissensgewinn ausgerichteten Zivilisation. Angewandte Ethik, philologisch präzise Exegese der Klassiker, szientistisch ausgerichtete Philosophie des Geistes, sich der Illusion ihrer Mathematisierung hingebende analytische Philosophie - das sind einige Facetten einer Disziplin, für die es immer nur vorwärts gehen soll und Probleme prinzipiell lösbar sind. Die Schrecken der Geschichte sind aus dieser Perspektive bedauernswerte Unfälle der Vergangenheit, wenn sie denn thematisiert werden. Kommen sie in der Gegenwart vor, fehlen Philosophen meistens die Worte. Der Glaube an die Zukunft, an eine optimale Lösung jeder Schwierigkeit, bleibt dennoch unerschütterlich. Vielleicht ist dieser Glaube naiver als wir denken, und unser optimistisch-narzisstisches Selbstverständnis verdient es, ab und zu erschüttert zu werden.

"Alle Träume, Philosophien, Systeme und Ideologien scheitern, wenn man sie mit dem grotesken Charakter des historischen Werdens konfrontiert. Die Dinge ereignen sich unbarmherzig, auf irreparable Weise; das Falsche, Arbiträre, Fatale triumphiert. Es ist unmöglich über die Geschichte nachzudenken ohne sich über sie zu grausen«, sagte Cioran 1983 zu J. L. Almira. ${ }^{26}$ "Die Geschichte kann mit einem Organismus verglichen

22 Vgl. ebd. und S. 35.

23 Vgl. ebd.

24 Ebd., S. 86.

25 John Cottingham: "What is Humane Philosophy and Why is it At Risk? «; in: Royal Institute of Philosophy Supplement, 65, 2009, S. 244.

26 J.L. Almira: Convorbiri cu Cioran, Bukarest 1993, S. 92 f. 
werden, das zuerst wächst und schließlich degeneriert. Der Mensch hätte sich nicht auf die Geschichte einlassen sollen, sondern ein statisches Dasein, nahe am Tiersein, führen sollen, ohne Hochmut und Ehrgeiz. Er hätte der prometheischen Verlockung nicht nachgeben sollen, denn Prometheus war der große Verleiter. Wie allen Wohltätern fehlte diesem die Einsicht. Er war naiv. Tatsächlich ist die Weltgeschichte nichts anderes als die Wiederholung von Katastrophen, in der Erwartung einer letzten Katastrophe. $\|^{27}$ "Jahrtausende lang waren wir bloße Sterbliche; endlich sind wir befördert worden in den Rang von Sterbenden " (Der zersplitterte Fluch, C, S. 1126). "Das Schauspiel der Menschheit - welch abscheuliches Ding! « (Lehre vom Zerfall, C, S. 7). "Als er nach fünf Jahren nach Hause kehrt und seine Frau umarmt, fällt Gulliver vor Ekel in Ohnmacht. Er kam aus dem Land der Pferde und konnte den Gestank des Menschentieres nicht ertragen. Der Mensch stinkt, ist ein stinkendes Ungetüm - das also ist Swifts Schlussfolgerung " (Cahiers, S. 686). "Denkt man an die Berliner Salons der romantischen Epoche, an die Rolle, die dort eine Henriette Herz oder eine Rahel Levin spielte, an die Freundschaft, die die letztgenannte mit dem Kronprinzen Louis-Ferdinand verband, und sagt man sich dann, dass diese Frauen in unserem Jahrhundert in einer Gaskammer geendet hätten, so kann man es sich nicht versagen, den Glauben an den Fortschritt als den falschesten und läppischsten Wahn anzusehen" (Vom Nachteil, geboren zu sein, C, S. 835).

\section{$I$.}

Deutsche Leser, die Cioran als Nihilisten, Skeptiker und Pessimisten kennen, werden vielleicht überrascht sein, dass es auch einen anderen Cioran gab, einen Cioran der Gewissheiten. Diese Phase fand vor seiner Emigration aus Rumänien nach Frankreich 1937 statt. Von den fünf Büchern, die er in Rumänien, auf Rumänisch, veröffentlichte, sind vier ins Deutsche übersetzt worden. Ohne das fehlende Buch, Die Verklärung Rumäniens, fehlt uns eine wichtige Facette von Cioran. Es erschien 1936, zu einem Zeitpunkt als die politische Situation im Land äußerst instabil war. König Carol II. ernannte nach Belieben Regierungen und suchte die stärker werdende faschistische Eiserne Garde durch Verbote zu neutralisieren. Schließlich sollte der König 1938 die Diktatur ausrufen, die 1940 von der faschistischen Diktatur des Generals Ion Antonescu abgelöst wurde, der an der Seite von Hitler-Deutschland in den Krieg gegen die Sowjetunion zog und sich maßgeblich am Holocaust beteiligte.

27 Ebd., S. 94 f. 
Die Verklärung Rumäniens ist gleichzeitig ein Dokument der rumänischen Hybris und Selbstverachtung. Cioran empfand sein Land als zutiefst primitiv und medioker, weil es sein Dasein am Rande der Geschichte friste, von der orthodoxen Kirche und dem trägen byzantinischen Geist an der freien Entwicklung behindert. Die Demokratie hielt er für zu rational und ineffizient, um dem Land schnell zur Glorie zu verhelfen. Die Lösung sollte ein "messianischer Furor« bringen. Daher plädierte er für eine rechte Diktatur als einzig mögliches Mittel zur Modernisierung Rumäniens. Cioran redete sich dabei in eine extremistische Raserei hinein. "Ein Volk mit dem Instinkt zur Freiheit muss den Selbstmord der Sklaverei vorziehen. Alle Mittel sind erlaubt, damit ein Volk sich einen Weg in die Welt bannt. Terror, Mord, Bestialität, Perfidie sind niederträchtig und unmoralisch nur in der Dekadenz [...]; wenn sie dem Aufstieg dienen, sind sie Tugenden. Alle Triumphe sind moralisch gut. [...] Ich liebe Rumänien mit einem schweren Hass ${ }^{28}{ }^{28}$

Cioran hat später seinen Freunden und seinen Tagebüchern anvertraut, dass sein faschistischer Parteigang ein Akt des Wahnsinns war, für den er nun »eine Art intellektuelle Scham» empfand (Cahiers, S. 695). Der rumänischen Neuauflage des Buches im Jahre 1990, aus der er die schlimmeren Passagen entfernte, stellte er die Erklärung voran, dies sei sein leidenschaftlichster, aber auch ihm fremdester Text. "Ich kann mich in ihm nicht wiedererkennen, obwohl meine damalige Hysterie offensichtlich ist. Ich sah es als meine Pflicht an, einige prätentiöse und dumme Seiten zu streichen« (Schimbarea la față, S. 5).

Vielleicht wird dieses Buch von Cioran nie ins Deutsche übersetzt werden. Der deutsche Leser kann aber seit kurzem auf eine Auswahl von Ciorans Artikeln zum selben Thema zurückgreifen, erschienen unter dem Titel Über Deutschland. Aufsätze aus den Jahren 1931-1937. Der Band enthält 25 Essays, alle in rumänischen Periodika erschienen, sowie ein nützliches Nachwort des Übersetzers, der auch viele erläuternde Fußnoten zum Text beisteuert. Wir finden hier frühe Texte über Dürer, Hegel, Kokoschka und Jaspers, neben Porträts von heute nicht mehr ganz so bekannten Figuren wie dem Denker Erwin Reisner und dem Dramaturgen Ferdinand Bruckner. Zu diesen eher kulturphilosophischen Artikeln gesellt sich 1932 der Aufsatz »Wohin geht die Jugend?«, der schon auf die imminenten politischen Entwicklungen hinweist. Das Jahr 1933 ist mit sieben Artikeln vertreten, darunter eine "Apologie Deutschlands«, ein »Deutscher Brief» und »Blicke auf Deutschland«, zwei Artikel mit Impressionen aus Berlin, sowie der längere Aufsatz »Deutschland und Frankreich oder die Illusion

\footnotetext{
${ }^{28}$ Cioran: Schimbarea la față a României, Bukarest 1990, S. 42.
} 
des Friedens". Aus dem nicht weniger ereignisreichen Jahr 1934 stammen fünf Artikel: "Die ethische Problematik in Deutschland", "Hitler im Bewusstsein der Deutschen", "Die Revolte der Satten«, sowie zwei unpolitische Essays: „Bayerische Melancholien« und »Hin zu einer anderen Sexualmoral«. Danach folgen Essays über »Das Christentum und das Ärgernis, das es in die Welt brachte (1935) und "Das Opfer der Massen« (1936). Der Band wird abgeschlossen mit vier Essays aus dem Jahre 1937: "Am Vorabend der Diktatur", "Der Verzicht auf Freiheit«, "Internationalismus und Universalismus" und "Zwischen europäischem und nationalem Bewusstsein«.

Ein Vorteil dieser Auswahl aus sieben Jahren liegt darin, dass sie die politische Entwicklung des Autors dokumentiert. Sein Ausgangspunkt war die deutsche Philosophie von Hegel bis Jaspers. In den ersten zwei Jahren nach Hitlers Machtergreifung steigerte sich Cioran zu einer unverblümten Bewunderung für den Diktator. Danach mäßigte sich sein Ton, 1937 sah er schließlich den Hitlerismus als Verhängnis an, wobei er weiterhin von der Notwendigkeit einer Diktatur in Rumänien überzeugt blieb.

Man muss es geradeheraus sagen: Es gibt untragbare Passagen in diesem Buch, vor allem aus den Jahren 1933-1934. Diese finden sich insbesondere in zwei Artikeln, die Cioran im Juli 1934 unter dem Eindruck des Röhm-Putsches schreibt. So heißt es im Artikel "Hitler im Bewusstsein der Deutschen «: "Es gibt keinen Politiker in der heutigen Welt, der mir größere Sympathie einflößte als Hitler. Es gibt etwas Unwiderstehliches im Schicksal dieses Mannes, für den jeder Lebensakt nur durch die symbolische Teilhabe am geschichtlichen Schicksal einer Nation Bedeutung gewinnt. [...] Die Führer-Mystik in Deutschland ist völlig gerechtfertigt. [...] Seine Reden sind von einem Pathos und einer Raserei durchdrungen, wie nur die Visionen eines prophetischen Geistes sie erreichen können. [...] Das Verdienst Hitlers besteht darin, einer Nation den kritischen Verstand geraubt zu haben. [...] Anderen die Verantwortung für den Weg, den sie einschlagen, zu nehmen, dies ist das dramatische Schicksal jedes Visionärs, Diktators und Propheten. [...] Hitler hat feurige Leidenschaft in die politischen Kämpfe gegossen und mit messianischem Atem einen ganzen Bereich der Werte dynamisiert, den der demokratische Rationalismus platt und trivial gemacht hatte. Wir alle brauchen eine Mystik, weil wir aller dieser Wahrheiten überdrüssig sind, aus denen keine Flammen schieBen." Kurze Zeit später, im Artikel „Die Revolte der Satten«, heißt es: "Es widert mich unendlich an, wenn ich von allen Seiten die immergleichen weinerlichen und sinnlosen Betrachtungen über das menschliche Leben höre. Da heißt es: [...] Der Mensch ist ein Wert an sich usw. usw. ... Aber ich will jedermann fragen: Was hat die Menschheit verloren, wenn eini- 
gen Schwachsinnigen das Leben genommen wurde? [...] In Deutschland gab es bloß eine Verschwörung der Anführer, eine Revolte von oben, eine Unzufriedenheit der Machtberauschten. Solchen Menschen das Leben zu nehmen, das Blut solcher Bestien zu vergießen ist eine Pflicht. Ein Diktator [...] ist verpflichtet, die Revolte der Satten zu ersticken. [...] Eine Bewegung, eine Strömung muss schwarze Flecken und vor allem rote aufweisen, damit die Taten feierlicher, endgültiger, gefährlicher werden«.

Trotz allem sind die hier versammelten Texte, exzellent übersetzt, lesenswert. Man erlebt hier nicht den Aphoristiker Cioran, sondern den Essayisten, Journalisten und Zeitzeugen, der in einer klaren Sprache Stimmungen und Strömungen der Zeit erfassen kann. Cioran erlebte die Nazifizierung Deutschlands aus nächster Nähe, 1933 bis 1935 als Student in Berlin. Dabei blickt er auf Deutschland mit den Augen eines Osteuropäers, was die bekannteren Beobachtungen westeuropäischer Besucher des Dritten Reiches (z.B. Jean Genet, Samuel Beckett, Christopher Isherwood, Albert Camus) ergänzt und mitunter bestätigt.

Im November 1933 berichtet er vom Gespräch mit einem zufällig getroffenen Deutschen, dessen Ansichten in der Bevölkerung weit verbreitet seien. Der unerschütterliche Pangermanismus dieses Mannes erstaunt selbst Cioran. „Die ganze französische Kultur«, so zitiert er seinen Gesprächspartner, sei »eine Lüge, ein oberflächliches Spiel«. Nur das Gotische in den menschlichen Werten sei anzuerkennen. "Selbst die Kunst der italienischen Renaissance sei in ihren großen Werken germanisch«. Die deutsche Wissenschaft sei nützlich für die Gemeinschaft, anders als die französische. Schließlich: »Deutschland ist kein zweitrangiges Land. Es wird Europa zeigen, dass es in der Politik die höchste Wirklichkeit ist. Der Völkerbund? Die größte französische Lüge«. Im Juli 1934 schreibt Cioran: "In Berlin hatte ich einmal Gelegenheit, einer Art kollektiver Ekstase um den Führer beizuwohnen. Anlässlich einer Feierlichkeit, in dem Augenblick, als Hitler die Straße Unter den Linden entlangfuhr, überfiel und umringte die Bevölkerung den Wagen, ohne - vor Staunen starr - ein Wort herausbringen zu können. Im deutschen Bewusstsein ist Hitler derart verwurzelt, dass nur große Enttäuschungen die Bevölkerung von einem solchen Kult abbringen können«.

Auch wenn Über Deutschland von den deutschen Rezensenten zumeist, und verständlicherweise, unter dem Blickwinkel von Ciorans Radikalisierung gedeutet wurde, ${ }^{29}$ lassen sich die Gedankengänge dieser Texte nicht darauf reduzieren. Cioran ist ein schillernder, wechselwendischer Autor. Wie in allen seinen Büchern finden wir auch hier denkwürdige Reflexionen über die menschliche Existenz, zu denen sich Erörterungen über die

${ }^{29}$ Siehe z. B. Die Zeit, 31.3.2011, FAZ, 8.4.2011, NZZ, 21.6.2011, SZ, 20.11.2011. 
deutsche Kultur im Speziellen gesellen. Cioran schneidet auch manche wichtige Frage über die politische Verfassung der Moderne an, vor allem im Hinblick auf die Möglichkeiten und Grenzen der Demokratie. Die Aktualität dieses Themas, da die Demokratie heute wieder gefährdet ist, liegt auf der Hand. Ciorans Kritik des "demokratischen Rationalismus", formuliert während der größten Demokratiekrise, könnte helfen, manche Ursachen der heutigen Probleme zu identifizieren. Jedenfalls haben wir es hier mit den politischsten Texten von Cioran zu tun; nie wieder wird er sich so intensiv mit der Frage nach der richtigen Gesellschaftsordnung auseinandersetzen wie in diesen Jahren.

II.

Eine Grundüberzeugung von Cioran ist, dass das menschliche Dasein eine "antinomische Struktur" hat, die sich auf vielfältige Art und Weise manifestiert, vor allem in Grenzsituationen. Der Gedanke ist nicht neu; schon Hume sprach von den Widersprüchen in der menschlichen Natur. ${ }^{30}$ In seiner 1932 verfassten Rezension von Jaspers' Psychologie der Weltanschauungen, listet Cioran z. B. folgende antinomische Paare auf: Form und Leben, Mechanisierung und Spontaneität, System und Geschichte, Norm und Erleben, Problematik und Intuition, Rationalität und Irrationalität, Transzendenz und Immanenz. Auch wenn Jaspers selbst von der antinomischen Struktur des Daseins spricht, ${ }^{31}$ finden sich diese Gegenpole so nicht bei ihm. Jaspers unterscheidet sorgfältig zwischen Antinomien auf der Objekt- und Subjektseite, d.h. zwischen Antinomien für das Erkennen und Handeln, und Antinomien in unseren Trieben, Charakterdispositionen und unserer Persönlichkeitsentwicklung. ${ }^{32}$ Zudem ist unsere antinomische Struktur für Jaspers konstitutiv für die menschliche Vitalität. "Unsere Existenz besteht zwischen Gegenpolen, die jeder für sich uns in ein Chaos oder in eine tote Daseinsform brächten, zusammen aber Entgegengesetztes fordern und wirken: Schulung und natürliches Wachstum, Sitte und Originalität, Form und Seelenhaftigkeit, Anpassung und Selbstbehauptung usw. ( $^{33}$ Von diesem natürlichen Antagonismus ist bei Cioran nicht die Rede. Er hält einen der Gegenpole für natürlich, den anderen für unnatürlich. Er schreibt: "[Jaspers' Buch] ist eine Reaktion auf den Hang zur Formalisierung des Lebens, die in dem Verlust des lebendigen und konkreten Inhalts besteht, und zwar durch das Ausscheiden der Erfahrung und die Vorherrschaft abstrakter und starrer Schemata. Die Schematisie-

\footnotetext{
${ }^{30}$ Siehe Hume: Principal Writings on Religion, a. a. O., S. 157.

31 Karl Jaspers: Psychologie der Weltanschauungen, Berlin 1919, S. 204.

${ }^{32}$ Ebd., S. $205 \mathrm{ff}$.

33 Ebd., S. 211.
} 
rung des Lebens ist gleichbedeutend mit dessen Verneinung «. Diese Beschreibung der Psychologie der Weltanschauungen mutet seltsam an, enthält doch gerade Jaspers' Buch viele Schemata und formale Unterscheidungen.

Eine kurze Reflexion ist hier angebracht. Was ist überhaupt eine "Schematisierung des Lebens « und warum ist sie abzulehnen? Nehmen wir das deutsche Handelsgesetzbuch (erlassen 1897). Darin wird das deutsche Handelsrecht definiert, zu dem beispielsweise die Bestimmung eines Kaufmanns im Rechtssinne und die verschiedenen Arten eines Handelsgeschäfts gehören. Sicherlich beruht dieses Handelsrecht auf Erfahrung. Doch es ist recht kompliziert und umfasst hunderte von Paragraphen. Cioran würde es wohl als wabstrakt» charakterisieren. Doch inwiefern verneint das Handelsgesetzbuch das Leben und was wäre die Alternative dazu? Wie sähe ein unschematisiertes, formloses, auch rechtlich ungeregeltes Leben aus, und warum wäre das zu bevorzugen? Weil Cioran uns nicht sagt, was er hier genau im Sinn hat, bleibt seine Position abstrakt, ein bloßer Slogan, eine vage Sehnsucht, die gerade nach festen Formen und Entscheidungen verlangt. Bemerkenswerterweise berührt Cioran selbst diesen Problempunkt in der Jaspers-Rezension, und zwar auf eine Weise, die schon hier den Keim für seine spätere Radikalisierung enthält - aber auch für ihre Überwindung. In seinem Grund, so Cioran, ist der Mensch ein unruhiges Lebewesen, von »tragischer Instabilität«, das sich nach Ruhe sehnt. Zwei Lösungen bieten sich in dieser Situation an. Entweder sucht er sich eine feste Daseinsumwelt zu bauen, einen "Halt im Begrenzten «" ${ }^{34}$, mit Weltanschauung, Ordnung, Normen, Institutionen und Besitztümern, oder er wehrt sich gegen eine solche Einkapselung und "Mechanisierung", und versucht im Offenen und Nichtbedingten der Grenzsituationen zu bestehen. Die erste Option ist die des Rationalismus. Jaspers, dem Cioran hier folgt, definiert den Rationalismus als bloße Formung ohne Lebenskraft, intellektuell, beweglich, heterogen, auf unmittelbare Zwecke bezogen, das Endliche verabsolutierend..$^{35}$ Die zweite Option ist die der Freiheit, des Nichtbedingten. Diese gibt es nur »in der lebendigen Erfahrung der Unendlichkeit«, schreibt Cioran. Er steigert sich gar zur offensichtlich falschen Behauptung, dass demjenigen, der im Begrenzten lebt, die Grenzsituationen (Tod, Schuld etc.) fremd sind. Eher scheint Cioran selbst hier von einfachen begrifflichen Schemata verblendet. Die Dualität Rationalismus-Freiheit, mit der Cioran hier operiert, stammt von Jaspers. Doch sind ihre Pole bei Jaspers, wie schon gesagt, in einer versöhnlichen Bewegung begriffen. Der Rationalismus überwindet sich selbst, indem er zwar von seinem endlichen Zweckdenken nicht ablässt (wie könnte es auch

\footnotetext{
${ }^{34}$ Siehe Jaspers: Psychologie, a.a. O., S. $269 \mathrm{ff}$.

35 Ebd., S. 270 ff.
} 
sonst ein menschliches Leben geben?), aber seine eigene Endlichkeit einsieht und sich dadurch in einer unergründbaren Unendlichkeit eingebettet sieht. Jaspers propagiert "ein Pathos des Unbedingten im Konkreten", der religiöse Anklänge hat ("vor Gott ist alles nichts») und durch Kants Vernunftideen artikulierbar ist. ${ }^{36}$ Diese Versöhnung mit unserer Grundlosigkeit ist kontemplativer Natur und hat keine direkte praktische oder gar politische Konsequenzen. Cioran dagegen stellt Jaspers' Position so dar, als wäre die »Rückkehr vom Abgrund des Nihilismus [...] gleichbedeutend mit der Erschöpfung der Lebenskräfte". Tatsächlich ist das Ciorans eigene Position zu diesem Zeitpunkt (1932). Sein Ideal ist das Innehalten im Unbegrenzten - eine aporetische Position, die ihn zuerst in den faschistischen Dezisionismus treiben wird, und danach, für den Rest seines Lebens, in die Einkapselung in die skeptische Muschelschale.

Die "Antinomie am Grund des Daseins" wird in dem ebenfalls 1932 erschienenen Essay "Hegel und wir« noch einmal thematisiert. Cioran rezipiert hier deutsche und österreichische Denker seiner Zeit, z. B. Richard Kroner, Eduard von Hartmann, Jonas Cohn, Arthur Liebert, Othmar Spann und Ernst Troeltsch. Er lehnt es ab, Hegel rein werkimmanent zu verstehen, und versucht den existentiellen Hintergrund von Hegels Philosophie, die »organischen Wurzeln« seiner Ideen zu eruieren. Cioran stellt Hegel als Romantiker dar, als einen, der die »Inkonsistenz der Lebensformen « in ein dynamisches, scheinbar objektives System fasst, dabei den Manifestationen des menschlichen Geistes doch nur wieder ein übergeordnetes subjektives Merkmal aufdrückt. Kroners Behauptung, Hegel sei »der größte Irrationalist, den die Geschichte der Philosophie kennt « ${ }^{37}$, stimmt Cioran allerdings nur bedingt bei. Was Hegel vor der »bitteren Lust« des Relativismus wahrt, d.h. dem "rationalistischen" Verharren im Konkreten, ist seine Auffassung der Vernunft als eines Absoluten, das malle Formen der Geschichte umgreift und [...] mit Sinn erfüllt«. Zwar sei diese Idee der Anwesenheit des Unendlichen im Endlichen durchaus eine romantische Vorstellung, aber das Besondere an Hegels Konzeption des Absoluten ist, dass es nicht jenseits der Geschichte steht, sondern sich in ihr und durch sie hindurch verwirklicht. »Der Wert des Wirklichen ist ohne dessen Geschichte undenkbar". Jaspers' versöhnlichere Dualismen klingen in diesen Gedanken an. Hegel, dem das menschliche Leiden nicht fremd gewesen sei, habe zwar eine tragische Auffassung des Lebens gehabt. Doch sein Verdienst liegt für den rumänischen Philosophen darin, die Inkonsistenz der Lebensformen nicht als statische, unüberwindliche Polarität anzusehen, als coincidentia oppositorum, sondern als die coincidentia discors der

\footnotetext{
36 Ebd., S. 272.

37 Richard Kroner: Von Kant bis Hegel, Band II, Tübingen 1924, S. 272.
} 
dialektischen Versöhnung. Man meint fast, Cioran ist so sehr von Hegels umfassenden System beeindruckt, dass seine eigene Radikalisierung für einen Augenblick aufgehoben ist. Gegen Ende des Aufsatzes zitiert Cioran gar einen Satz von Hegel, der seine spätere melancholisch-skeptische Haltung vorwegnimmt: "Die Weltgeschichte ist nicht der Boden des Glücks. Die Perioden des Glücks sind leere Blätter in ihr. ${ }^{38}$

Schon im nächsten Artikel, "Wohin treibt die Jugend? (November 1932), klingt ein düsterer Ton an. Der junge Mensch seiner Zeit (Cioran ist 21 Jahre alt) leidet an seiner eigenen Modernität, an einer exzessiven Beweglichkeit, »die ein dauerndes Festhalten an einem Inhalt oder einer Form unmöglich macht, und eine Vorstellung binnen kurzem beseitigt, um sie durch eine andere von eben so flüchtiger Dauer zu ersetzen«. Diese Wechselhaftigkeit aller Anschauungen zeitigt und wird gezeitigt von einer Ungewissheit in der Gegenwart und einer Angst vor der Zukunft. Sie hat keine bloß materiellen Ursachen (marxistische Erklärungen werden implizit abgelehnt), sondern ist ein Aspekt der tiefen Kulturkrise der Zeit, vor allem in Deutschland und Rumänien (und auch in Russland, wie er in einem anderen Artikel betont). Warum gerade diese Länder davon betroffen sind, und warum Frankreich, von Cioran mit dem Stempel der »Mittelmäßigkeit« versehen, von der Krise nicht betroffen sein soll, erfahren wir nicht. Bemerkenswerterweise widerspricht Cioran dem Optimismus bei Mircea Eliade (auch er sollte bald zum Faschisten werden), der in der existentiellen Ergriffenheit der Jugend eine Aufbruchstimmung sieht. Cioran schlägt dunklere Akkorde an. Die Verzweiflung an der dämonischen Welt, gepaart "mit einer wollüstigen Bejahung dieses Dämonismus«, die perverse Befriedigung aus der Erfahrung des Nichts - diese Dinge sind auch Manifestationen des Lebendigseins. Zwar erklärt Cioran zunächst, dass es ihm nicht um die politische Ausrichtung der Jugend geht, doch seine Analyse, ja die Sprache, in der sie verfasst ist, belegen, wie nahtlos der Übergang von diesem vitalistischen Furor zu einer extremistischen Politik sein kann. Cioran schreibt als Diagnostiker, wo er vom »quälenden Feuer» der Jugend spricht, »dessen Hitze und Flammen alles verbrennen und verzehren«. Manche seiner Sätze klingen wie die Drohungen jenes Unheils, das dann tatsächlich kam: »Uns jungen Leuten wird auf verhängnisvolle Weise mit allem zu brechen auferlegt. [...] Die Stunde der Jugend [Eliades Begriff] hat geschlagen. Aber nicht in einem klassischen und normalen Rhythmus, sondern in einem vorankündigenden und apokalyptischen«.

Ein Jahr später ist Cioran in Hitlers Deutschland angekommen, im wörtlichen und übertragenen Sinne. Er schreibt in einem »Deutschen

${ }^{38}$ G. W. F. Hegel: Vorlesungen über die Geschichte der Philosophie, Frankfurt a. M., S. 41 f. 
Brief", dass er sich endlich in einem politischen Kontext befindet, der nicht platt und widerwärtig ist, weil hier, anders als in Demokratien, die politischen Werte nicht von den sonstigen Werten der Kultur, Kunst etc. getrennt sind. Dass dabei der Rassismus offen propagiert wird, findet Cioran nicht weiter schlimm, denn Deutschland fühlt sich unter diesem Regime "wohl, frisch und vital.. Die zehntausenden Mitglieder der KPD, die zu diesem Zeitpunkt in den NS-Gefängnissen lagen oder schon tot waren, gehören nach dieser Logik schon nicht mehr zu Deutschland. Auch der diktatorische Charakter des Regimes beunruhigt Cioran nicht. Im Gegenteil, an der Diktatur begeistert sich der Bürger mehr als an der "schalen Demokratie mit ihren Illusionen von Volksvertretung und [ihrer] skandalösen Atomisierung". Die Demokratie mag auf dem Papier bewundernswert sein, praktisch ist sie dem Menschen unzugänglich. Weil sie dies angeblich nicht einsehen, vermögen Demokraten nicht zu erklären, warum die Diktatur die Demokratie in Deutschland ablösen musste.

Ciorans Urteile werden heute mit Recht als unmöglich beurteilt. Dass die Weimarer Republik verfassungsrechtliche Schwächen hatte, kommt ihm z. B. nicht in den Sinn. Wie andere anti-liberale Denker seiner Zeit, auch Martin Heidegger oder Carl Schmitt. ${ }^{39}$ Stattdessen polemisiert er gegen Rationalismus, „Legalismus und Juridismus«, begeistert sich für die Mischung aus Barbarei und Enthusiasmus im politischen Irrationalismus, und bemüht martialische Metaphern wie "Sieg der Lebenskraft" und "Steigerung der Lebenskräfte im Kampf mit den veralteten Formen«. Cioran, in der politisch-juristischen Analyse ungeschult (ein altes Desideratum seines Heimatlandes), übernimmt faschistische Floskeln, ohne zu sehen, dass sie zum propagandistischen Arsenal des Nazismus gehörten.

Die nächsten Artikel, die vor einer Glorifizierung Hitlers (und im übrigen auch Lenins) nicht halt machen, wurden schon angesprochen. Die Beiträge von 1937 zeugen dann immerhin von einer gewissen Ernüchterung. Er unterscheidet jetzt zwischen der Diktatur als einer in besonderen Zeiten notwendigen Herrschaftsform und der Diktatur als einer dauerhaften Form. Wie schon in Die Verklärung Rumäniens (1936) sieht er im Essay "Am Vorabend der Diktatur" (Februar 1937) für Rumänien die Stunde der Diktatur gekommen, weil das Land ansonsten seiner Rückschrittlichkeit nicht entkommen kann. Einer dauerhaften Diktatur erteilt er zwar die Absage. Doch Cioran erwägt nicht, wie eine Diktatur zu beenden wäre.

Immerhin beginnt er die Schattenseiten des Nazismus zu sehen. „Was mir am Hitlerismus beunruhigend und mitreißend schien, war ein Grundzug von Verhängnis, von kollektiver Unerbittlichkeit, so als seien alle

39 Siehe Carl Sснмitт: Die geistesgeschichtliche Lage des heutigen Parlamentarismus, Berlin 1923. 
Menschen Werkzeuge eines dämonischen Wesens, bis hin zur Schwachsinnigkeit fanatisiert im Helldunkel der Gegenwart. Dem Hitlerismus verfält man«. Er sieht im Faschismus, Nazismus und auch im Kommunismus zwar "große Schicksalsmächte«, doch betont er jetzt stärker das Janusgesicht dieser Bewegungen.

Im Artikel »Der Verzicht auf Freiheit« (März 1937) betont er noch einmal seine Vorbehalte gegen die liberale Demokratie. Sie führe zur Atomisierung der Gesellschaft und somit zu ihrer eigenen Aufhebung, da sie das Bedürfnis nach Einheit (in der Diktatur) verstärkt. Der Abbau der Demokratie liege am Wesen der Freiheit selbst, nichts verschleiße sich stärker als diese. Cioran denkt zwar nicht über Möglichkeiten nach, diesem Verschleiß entgegenzuwirken, doch immerhin ist er von diesem Verschleißprozess nicht mehr so begeistert wie in den Jahren zuvor. „Und so ist bei den Intellektuellen unserer Zeit eine sonderbare Unterwerfungslust, eine Notwendigkeit der Verblendung, eine Wollust des Niederkniens entstanden. Niemand will mehr frei sein. Darin muss der Ursprung der Leidenschaft für die Rechte oder die Linke gesucht werden«. In diese Diagnose mischt sich zudem ein neues Element, das in Die Verklärung Rumäniens noch fehlte, und auf den späteren Cioran hinweist: "Einem in himmelblauen Trauerflor eingehüllten Herzen ist das Schauspiel der Welt durch ontologischen Überdruss, eine feinstoffliche Klosterlangeweile oder eine elementare Bordelllangeweile entstellt. Alle Klarsichtigkeit ist verbrecherisch. Deshalb: Die Diktatur komme! «In einem Artikel von 1940 (nicht enthalten in Über Deutschland) wird er ähnlich argumentieren; die Extremisten handeln nicht, weil sie wirklich ein Land revolutionieren wollen, sondern weil sie eine unerträgliche Leere in sich spüren. ${ }^{40}$ Dieser »ontologische Überdruss", der im Grunde alles oder nichts motivieren kann, sollte Cioran bald dazu führen, sich aus der Politik ganz herauszuhalten.

Sicherlich trugen Ciorans extremistische Artikel zur Radikalisierung mancher junger Rumänen bei. Seine Abwendung von der Politik befreit ihn nicht von dieser politischen Schuld. Ein wirkungsvolleres »Mea culpa» hätte darin bestanden, sich nach der faschistischen Episode für den Aufbau einer demokratischen Bewegung in Rumänien einzusetzen. Doch gerade auch weil Cioran und seine Generationskollegen sich aus den eigentlichen politischen Handlungsprozessen heraushielten, tragen sie eine Mitschuld am Scheitern der Demokratie in Rumänien, wie Eliade in selbstkritischem Rückblick feststellte. ${ }^{41}$

40 Zitiert in Marta Petreu: Un trecut deocheat sau »Schimbarea la față a României«, Bukarest 1999, S. 311 f.; engl. Übersetzung: An Infamous Past: E.M. Cioran and the Rise of Fascism in Romania, Chicago 2005.

41 Siehe Mircea Eliade: »I-a mâncat capul politica«; in: Indreptar, I:9, 1951. 
Im Essay, "Internationalismus und Universalismus" (Mai 1937), unterscheidet Cioran zwischen zwei Formen des Nationalismus, von denen einer im »Tellurischen« bleibt, d.h. provinziell und volksverhaftet ist, während der andere nach universeller Geltung strebt, wie z. B. der Panslawismus Dostojewskis, die Idee der Rettung der Menschheit durch das russische Volk. ${ }^{42}$ Diese zweite Art von Nationalismus muss schon universale Werte vertreten. Cioran zieht diesen Nationalismus dem provinziellen vor, und hält ihn auch für überlegen gegenüber dem "Internationalismus", der alles, auch die Werte, in funktionale Beziehungen verwandelt. Diesen Internationalismus sieht er in Amerika verkörpert, das bloß Güter, und keine Werte, in Umlauf setzt. Dem Internationalismus fehlt es an geistiger Intensität und Kreativität. Cioran bemüht hier, wie auch Heidegger zur ungefähr gleichen Zeit, antiamerikanische Klischees. ${ }^{43}$

Sieben Monate später schreibt Cioran den Essay "Zwischen europäischem und nationalem Bewusstsein". Hier ist kaum noch etwas von der früheren nationalistischen oder gar faschistischen Begeisterung zu merken. Der Spenglersche Pessimismus ist nun stärker. Der Nationalismus bietet zwar »etwas Positives, befriedigt aber nicht den Geschmack für das Absolute«. Zudem trägt er zum Untergang Europas bei, weil er die Nationen partikularisiert, während der europäische Geist auf das Universale ausgerichtet ist. Auch hier drängen sich Parallelen zur Gegenwart auf. »Indem jedes Volk zu seiner besonderen Tradition zurückkehrte [...], zerbrach die abstrakte, auf den Trümmern der Partikularismen errichtete Einheit Europas. [...] Universalistische Kulturen werden auf der Idee der Humanität aufgebaut; der Vitalismus mit seinem impliziten Kult der Kraft isoliert die Nationen monadisch«. Im Dezember 1937 weilt Cioran schon mit einem Promotionsstipendium in Paris. Er sollte nur noch einmal nach Rumänien zurück kehren, im Herbst 1940. Zwar gibt es noch extremistische Rückfälle, etwa einen Artikel von Dezember 1940, in dem Cioran mitten in der faschistischen Diktatur in Rumänien den inzwischen hingerichteten Anführer der Eisernen Garde, Ion Zelea Codreanu, auf schamlose Weise glorifiziert ${ }^{44}$. Nach seiner endgültigen Rückkehr nach Frankreich im Februar 1941 lässt er all das hinter sich, schreibt aber noch eine Zeit lang auf Rumänisch und verfasst während des Krieges mehrere Texte des Übergangs, vor allem den Leidenschaftlichen Leitfaden ${ }^{45}$ sowie einen längeren Text Über Frankreich: „Bedarf denn Europa, nach so vielen Fanatismen, nicht einer Flut von Zweifeln? Bereiten wir uns denn nicht alle auf

\footnotetext{
${ }^{42}$ Siehe Fjodor Dostojewski: Tagebuch eines Schriftstellers. Notierte Gedanken, München/Zürich 1992, S. $225 \mathrm{ff}$.

${ }^{43}$ Martin Heidegger: Einführung in die Metaphysik, Tübingen 1953, S. 28 f.

${ }^{44}$ Siehe Petreu: Un trecut, a. a. O., S. $327 \mathrm{ff}$.

${ }^{45}$ Emil Cioran: Leidenschaftlicher Leitfaden, Frankfurt a. M. 1996.
} 
einen Weltschmerz vor, in dem Frankreichs Beitrag einer der verführerischsten wäre? Wenn Frankreich noch einen Sinn hat, so denjenigen, den Skeptizismus, zu dem es fähig ist, zur Geltung zu bringen, uns die Formel der Unsicherheiten zu geben oder unsere Gewissheiten zu zermahlen«. Das ist schon sehr nahe an der heilsamen Kraft des Zweifels, über die er später schreiben wird, z.B. in Vom Nachteil, geboren zu sein: "Sobald ich einen Zweifel formuliere, [...] empfinde ich eine seltsame, aufwühlende gute Stimmung. Es fiele mir viel leichter, ohne eine Spur von Überzeugung zu leben als ohne eine Spur von Zweifel« (C, S. 802). Im ersten Teil vom Leidenschaftlichen Leitfaden sind zwei Fluchtbewegungen von allem allzu Konkreten, Geschichtlichen, Politischen zu bemerken, zum einen die Flucht in den Skeptizismus und Nihilismus, zum anderen die Flucht in die (rumänische) Sprache, in eine Sprache voll überbordender Metaphern. "Ästhetische Nirvanisierung der Welt: Das Höchste in höchstem Schein erringen. Nichts und alles sein im Schaum des Unmittelbaren. Und zu den Rändern des Ichs emporfahren, ins Unbedingte und Flüchtige. "Diese mal lyrisch mal unsinnig wirkenden Sprachkonstrukte werden nicht jedem Leser gefallen. Der Übersetzer gibt zwar sein Bestes, doch scheitert auch er manchmal an der Tatsache, dass Cioran im Leidenschaftlichen Leitfaden das alte Kirchenrumänisch nachempfindet. Wir sollten aber nicht vergessen, dass Cioran schon in "Am Vorabend der Diktatur» (1937) schrieb: »Um in Deutschland nicht vom Hitlerismus angesteckt zu werden, habe ich begonnen, den Buddhismus zu studieren«. Für Ciorans tiefer gehende Affinitäten zum Buddhismus sei auf Jürgen Großes Analyse hingewiesen. ${ }^{46}$

Der zweite Teil von Leidenschaftlicher Leitfaden, erst nach Ciorans Tod 1995 entdeckt und vor kurzem ins Deutsche übersetzt, vertieft die nihilistischen Sehnsüchte, die im Grunde aporetisch sind. „Ich habe unablässig geträumt von einem Land ohne Menschen, ohne Klima, ohne Ideale, neutral gegenüber der Erde und gegenüber den Gestirnen, das nicht dem Leben und vielleicht auch nicht einmal dem Tode gleicht, ein Reich schwachsilbernen Reifs, auf das ich meine Augen heften würde, behext von der Versuchung des zauberischen Nichtdaseins". Auch hier finden sich kitschige Passagen ("Jemand müsste dennoch für mich beten, seine Hände hin zum Himmel zusammenlegen, damit seine Finger die Flügel eines nachdenklichen Engels berühren«). Insgesamt dominieren die Leitmotive des späteren, französischen Werks: »ontologischer Überdruss", „Schwere des walachischen Bluts«, »Wüste des Herzens«, menschliche Hinfälligkeit, Kulturpessimismus, das Apokalytische, die Kälte des gesamten Weltalls. "Nicht die Finsternis ist das Unwahrscheinliche in der Welt; sie ist die Si-

\footnotetext{
${ }^{46}$ Grosse: Erlaubte Zweifel, a. a. O., S. $34 \mathrm{ff}$.
} 
cherheit unserer Knochen. Die Nacht stöhnt in deren Mark und dem der Gedanken. In den Knöcheln und im Schädel haucht das Licht seinen Geist aus." Dazwischen mischen sich recht viele Bemerkungen über die Musik und die Liebe, die ihn eher als Melancholiker denn als Nihilisten offenbaren. Zwar "[fühlst du] nur an der Seite der Frau, wie morsch du bist«. Dennoch: »Ohne Liebe ist alles nichts«.

Auch wenn er als Nihilist, Skeptiker und erst recht als politischer Denker gescheitert ist, fällt es schwer, ein letztes Urteil über Cioran auszusprechen.

Edward Kanterian

University of Kent

School of European Culture and Languages

Department of Philosophy

Canterbury, United Kingdom

E.Kanterian@kent.ac.uk 